

\title{
Market sharing agreements and collusive networks*
}

\author{
Paul Belleflamme ${ }^{\dagger} \quad$ Francis Bloch ${ }^{\ddagger}$
}

October 11, 2001

\begin{abstract}
This paper analyzes the formation of market sharing agreements among firms in oligopolistic markets and procurement auctions. The set of market sharing agreements defines a collusive network, and the paper provides a complete characterization of stable and efficient collusive networks when firms and markets are symmetric. Efficient networks are regular networks, where firms have the same number of market sharing agreements. Stable networks are formed of complete alliances, of different sizes, larger than a minimal threshold. Typically, stable networks display fewer market sharing agreements than the optimal network for the industry and more market sharing agreements than the socially optimal network. When firms or markets are asymmetric, incomplete alliances can form in stable networks, and stable networks may be underconnected with respect to the social optimum.
\end{abstract}

JEL Classification Numbers: D43, D44

Keywords: market sharing, collusion, economic networks, oligopoly, auctions.

${ }^{*}$ We are grateful to participants in the Vth Conference of the Society for the Advancement of Economic Theory (Ischia, 2001) and the Warwick 2001 Summer Workshop for their comments.

${ }^{\dagger}$ Department of Economics, Queen Mary, University of London (UK), p.belleflamme@qwul.ac.uk.

${ }^{\ddagger}$ GREQAM and Ecole Superieure de Mecanique de Marseille (France), bloch@ehess.cnrsmrs.fr 


\section{Introduction}

The literature on collusion focuses on price-fixing agreements. Studies of collusion on oligopolistic markets typically assume that firms agree on prices and production quotas, and studies of collusion in auctions generally model bidding rings as groups of bidders agreeing on a distribution of bids submitted in the auction. In this paper, we analyze an alternative form of collusion - market sharing agreements - which has increasingly attracted the attention of competition authorities. For example, in a recent report, the Irish Competition Authority (1999) notes:

As an alternative to a price-fixing cartel, firms can attempt to achieve the same effect by other means, e.g. they may divide up the country between them and agree not to sell in each others designated area, thereby enabling each to set prices knowing that the others will not undercut them. At its simplest, a market-sharing cartel may be no more than an agreement among firms not to approach each others customers or not to sell to those in a particular area. This may involve secretly allocating specific territories to one another or agreeing on lists of which customers are to be allocated to which firm. Market-sharing agreements may have two aspects. Firstly, firms may decide on the share of the market or level of business that each is to get. Secondly in order to achieve this objective they may then get together regularly to decide which firms will get particular contracts.

The existence of market sharing agreements in oligopolistic markets and procurement auctions has long been recognized by antitrust authorities ${ }^{1}$, but evidence suggests that the number of cases involving market sharing agreement has increased in recent years. With the emergence of the common market, the European Commission has been particularly aware that producers from different

\footnotetext{
${ }^{1}$ One of the earliest antitrust cases brought under the Sherman Act, the Addyston Pipe Case (1898), dealt with a group of six producers of cast iron and water pipes in the Middle West and the West, which rigged prices quoted to buyers in certain cities, and reserved other cities as the exclusive domain of one seller. (Scherer and Ross, p. 318).
} 
countries may enter market sharing agreements to protect their home markets. In a landmark case against Solvay and ICI, in 1990, the European Commission has established that the two companies had operated a market sharing agreement for many years by confining their soda-ash activities to their traditional home markets, namely continental western Europe for Solvay and the United Kingdom for ICI. It was also found that over many years, all the soda-ash producers in Europe accepted and acted upon the 'home market' principle, under which each producer limited its sales to the country or countries in which it had established production facilities. ${ }^{2}$ Very recently, airline alliances have also become the target of investigation by the European Commission. In July 2001, the Commission has decided to fine Scandinavian airlines SAS and Maersk Air 39.375 and 13.125 million euros respectively for operating a secret agreement that led to the monopolization by SAS of the Copenhagen - Stockholm route, as well as to the sharing of other routes to and from Denmark. ${ }^{3}$ In the United States, recent cases of market sharing agreements in procurement auctions are quoted by Pesendorfer (2000), who provides empirical evidence that in Texas, contracts for the delivery of milk to school districts operated under a secret market sharing agreement. In another recent case, GTE New Media Services has alleged that Netscape, Yahoo! and the regional telephone companies (RBOCs) created an illegal cartel designed to exclude GTE from the internet yellow pages market. In its decision, ${ }^{4}$ the court noted that the agreement among the RBOCs to divide the internet yellow pages service along geographic lines could amount to a per se illegal horizontal market-sharing agreement, violating the Sherman Act (Maxwell and Reznick, 2001). In Australia, the antitrust authority has recently brought evidence of market sharing agreements in different industries. In the recyclable waste paper industry, firms agreed to withdraw competitive quotes to acquire recyclable waste paper in specific areas and allocated customers among themselves. In the regional newspapers sector, one publisher withdrew its plan to extend the coverage of its newspaper to another region after the incumbent publisher in that region threatened to retaliate. In the metal recycling industry, large producers employed bullying tactics to intimi-

\footnotetext{
${ }^{2}$ See Official Journal L $152,15 / 06 / 1991$, pp. 1-15.

${ }^{3}$ See Press Release - IP/01/1009 - 18.07.2001 of the European Commission.

${ }^{4}$ GTE New Media Services Inc. v. Ameritech Corp., 21 F. Supp. 2d 27, 38 (D.D.C. 1998).
} 
date smaller competitors into market sharing. ${ }^{5}$

The objective of this paper is to analyze the formation of market sharing agreements among firms. Do market sharing agreements always lead to the monopolization of the market? Can groups of firms sign market sharing agreements among themselves but compete on outside markets? When do competing alliances of firms emerge on the market? Is it possible that two firms sign a market sharing agreement with a third, but compete against each other? What are the anti-competitive effects of market sharing agreements, and what is the socially efficient configuration of markets?

In order to answer these questions, we appeal to the recent theory of economic networks, developed, among others, by Jackson and Wolinsky (1996) and Goyal (1993). ${ }^{6}$ We consider a model where firms are originally specialized on one market and compete either as oligopolists or as bidders in a procurement auction. By signing bilateral agreements, firms can commit to stay out of each other's market. The set of bilateral agreements defines a network of collusive links, and each firm's profit can be expressed as a function of the network. Following Jackson and Wolinsky (1996), we characterize the efficient and stable networks which form on the market.

In the baseline model, we assume that firms and markets are symmetric (there is no entry cost on a foreign market, and all markets have the same size). Our main result characterizes the set of stable networks, under a minor restriction on the profit function (we assume that on each market, a firm's profit is log-convex in the number of active firms on the market). We show that a stable network can be decomposed into complete components of different sizes, all larger than a given lower bound. In economic terms, this result shows that firms form complete alliances (when two firms are linked to a third, they are also linked to each other), that competing alliances of different sizes can emerge, and that alliances must reach a critical size to be stable. This result stems from the convexity of profits in the number of active firms on the market. In a collusive network, all firms have an incentive to free-ride on the market sharing

\footnotetext{
${ }^{5}$ See, respectively, Australian Competition and Consumer Commission (1998, 1999), and Australian Broadcasting Corporation (2000).

${ }^{6}$ See also Bala and Goyal (2000) and, for a complete survey of the literature, the recent book by Slikker and van den Nouweland (2001).
} 
agreements signed by the others: the less firms are active on any given market, the higher the profit of every firm on that market. However, as profits are log-convex, the incentive to sign a market sharing agreement increases with the number of firms belonging to an alliance. Hence, alliances have to be complete and must attain a minimal size to be stable. Furthermore, when competing alliances emerge, they have to be of different sizes, with members of the smaller alliance free-riding on the market sharing agreements signed by the members of the larger alliance.

We distinguish between two notions of efficiency: a network is efficient if it maximizes total industry profits and socially efficient if it maximizes social surplus. As markets are independent, the maximization of total industry profits and social surplus amounts to maximizing total industry profits and social surplus on every market. Hence, efficient and socially efficient networks are characterized by the number of active firms on each market, or alternatively by the identical number of links of each firm in the network. ${ }^{7}$ We show that stable networks are under-connected with respect to efficient networks. In other words, the free-riding incentives typically prevent firms from reaching the network which maximizes total industry profits. On the other hand, in all the applications we consider, it is socially efficient for all firms to be present on all markets, and stable collusive networks are over-connected with respect to the socially efficient network.

A distinguishing feature of our analysis is the modelling of collusive links as bilateral agreements. Bilateralism is also reflected in the stability concept of Jackson and Wolinsky (1996), who only allow links to be formed and destroyed on a pairwise basis. Introducing the possibility of multilateral agreements or coordinated strategies for a firm on different markets drastically changes the characterization of stable networks. We show that when firms can simultaneously renege on all their market sharing agreements, the set of stable collusive networks is seriously reduced. Typically, this stronger stability criterion imposes an upper bound on the size of alliances, as a firm's incentive to renege on all its market sharing agreements is higher for larger alliances.

\footnotetext{
${ }^{7}$ In the graph theoretical terminology, these networks are called regular networks.
} 
We apply our results to specific models of oligopoly and private value auctions. In a Cournot oligopoly with homogeneous products, different specifications of demand give rise to sharply different configurations of stable networks. In a model with iso-elastic demand, stable networks typically contain only one very large alliance; in a model with exponential demand, stable configurations can be fragmented into a large number of small alliances. We also compare stable networks under Cournot and Bertrand competition in a model with differentiated commodities. Not surprisingly, we find that the incentives to sign market sharing agreements are higher under price competition than under quantity competition, and that stable alliances are easier to sustain in the Bertrand model. Finally, we consider private values procurement auctions, and give an exact characterization of stable networks for different distribution functions on the firms' costs. We find that stable alliances are typically quite large, and that some stable network configurations allow for the presence of independent firms which free-ride on the formation of the large alliance. It should be noted that, in all our applications, when firms can simultaneously destroy all their collusive links, the set of stable alliances is drastically reduced. In fact, in many examples, no stable alliance survives the stronger criterion of stability.

One of the main defenses of firms involved in market sharing agreements is the existence of entry costs which naturally prevent firms from entering each other's market. To assess the validity of this argument, we analyze, in an extension of our baseline model, the formation of market sharing agreements in the presence of asymmetries. We show that when firms benefit from an incumbency advantage on their home market, their incentive to sign market sharing agreements is strengthened. When foreign firms face a fixed entry cost, connected firms form the same number of market sharing agreements, and the collusive network is typically denser than in the absence of entry costs. However, an example suggests that, from a social point of view, firms may still be present on too many markets in the stable collusive network. When foreign firms face unit transportation costs, the general characterization of stable networks becomes impossible. In an example, we show that the presence of a transportation cost increases the number of market sharing agreements, and that some stable collusive networks display incomplete alliances where two firms may be linked to 
a third, but compete among themselves. Finally, we analyze a situation where markets are asymmetric, and can be ranked by profitability. We show that, in a stable network, firms on less profitable markets sign more market sharing agreements than firms on more profitable markets. Again, we provide an example to show that this may result in the formation of an incomplete alliance, where two firms with very profitable home markets compete among themselves but sign a market sharing agreement with a third firm, located on a less profitable market.

Starting with Stigler (1950)'s seminal contribution, the stability of pricefixing cartels has been extensively studied in the literature. (See Selten (1973) and d'Aspremont et al. (1983) in the case of Cournot oligopolies and Deneckere and Davidson (1985) for a Bertrand model with differentiated commodities and Nocke (1999) for a recent contribution discussing the earlier literature.) In auctions, the study of the stability of bidding rings is much more complex, as it requires the analysis of auctions with asymmetric bidders. Mailath and Zemsky (1991) study stability of bidding rings in the simpler context of second-price auctions, and Mac Afee and Mac Millan (1992) provide an example in the case of first-price auctions. ${ }^{8}$ In spite of basic differences between our model and traditional models of collusion in oligopolies and auctions, the stability of collusive networks bears a close resemblance to the stability of bidding rings and price-fixing cartels. As firms benefit from the formation of collusive agreements by other firms, free-riding incentives threaten in the same way the stability of price-fixing cartels, bidding rings and collusive networks. As in the case of cartels and bidding rings, our characterization of stable collusive networks results from the balance between free-riding incentives and the benefits of collusion.

In a series of papers closely related to our work, Goyal and Joshi (2000a) and (2000b) and Goyal and Moraga (2000) apply the theory of economic networks to models of oligopoly. Goyal and Joshi (2000a) and Goyal and Moraga (2000) study the formation of cost-reducing alliances. By signing bilateral agreements, firms can benefit from synergies in production and lower their production costs.

\footnotetext{
${ }^{8}$ In general first-price auctions, Pesendorfer (2000) presents partial characterization results on the equilibrium of an auction with a bidding ring and independent bidders. However, the issue of stability of the bidding ring is not addressed in the model.
} 
Goyal and Joshi (2000a) characterize stable networks when the cost reduction is exogenous, and Goyal and Moraga (2000) study a model where firms make bilateral investments to reduce their costs. While the methodology they use is similar to ours, the stable networks they characterize have no relation to stable collusive networks. The main difference stems from a difference in the sign of external effects in the two models. In cost-reducing alliances, the formation of a link has negative effects on outsiders, whereas the formation of a link has a positive effect on outsiders in the case of market sharing agreements. ${ }^{9}$ Goyal and Joshi (2000b) study the formation of bilateral trading agreements in an international oligopolistic market. In spite of differences in the motivations, the model they study is formally very similar to ours, as bilateral trading agreement enabling firms to enter each other's market can be interpreted as the converse of market sharing agreements by which firms commit to stay out of each other's market. There are two important differences in the analyses. First, Goyal and Joshi (2000b) only consider a Cournot oligopoly with linear demand, whereas we study general profit functions, encompassing different models of oligopoly and auctions. Second and more importantly, the objective functions of the actors in the two models are different. Goyal and Joshi (2000b) model countries' objective functions as the sum of the home firm's profit, consumer surplus in the home country and import tariffs, whereas we suppose that firms only maximize profits. As a consequence, the stable networks in the two models are very different.

The rest of the paper is organized as follows. In the next section, we describe the general model of market sharing and characterize efficient, stable and strongly stable collusive networks. In Section 3, we discuss the application of our model to oligopolistic markets and procurement auctions. In Section 4, we extend our baseline model to take into account asymmetries among markets and firms. In Section 5, we conclude and discuss the limitations of our model.

\footnotetext{
${ }^{9}$ This difference between positive and negative external effects also appears in the formation of price-fixing cartels and cost-reducing associations in oligopolies. (See Bloch (1997) and Yi (1997).)
} 


\section{Networks of Market Sharing Agreements}

\subsection{The Model}

We consider $N$ firms indexed by $i=1,2, . . N$. We associate to each firm a market on which it is initially active. In the oligopolistic context, the market of firm $i$ can be interpreted as its home market, and in the context of auctions, we assume that each bidder has privileged access to one of the procurement auctions. For any market $i$, we denote by $n_{i}$ the number of active firms on the market. We consider a reduced form profit function on each market, which could arise either from oligopolistic interaction or from bidding competition, and which only depends on the number of active firms on the market. We let $\pi_{i}^{j}\left(n_{i}\right)$ denote the profit of firm $j$ on market $i$. In the benchmark model, we suppose that all markets are identical, and all firms are symmetric, so

$$
\pi_{i}^{j}\left(n_{i}\right)=\pi\left(n_{i}\right) \forall i, j
$$

We suppose that the profit function satisfies the following axioms.

Axiom 2.1 Individual profits are decreasing in the number of firms active on the market, $\pi(n) \leq \pi(n-1)$.

Axiom 2.2 Individual profits are log-convex in the number of firms active on the market, $[\pi(n+1)-\pi(n)] / \pi(n+1) \geq[\pi(n)-\pi(n-1)] / \pi(n)$.

Axiom 2.1 is a very intuitive condition, which guarantees that an increase in the number of competitors reduces the profit of each firm. In the next section, we show that this axiom is satisfied in all models of auctions and oligopolies. Axiom 2.2 is more difficult to satisfy, and embodies an important structural property of profits. It indicates that the rate of decline of profits is itself increasing in the number of firms. Clearly, this axiom is stronger than convexity of profits. In the next section, we provide sufficient conditions on oligopoly models under which this axiom is satisfied, and show that profits are always log-convex in private value auctions.

In addition to individual profits, we define total profits on the market as $T(n)=n \pi(n)$. Depending on the context, we will define various measures of welfare on each market, denoted $W(n)$. 
Each pair of firms $(i, j)$ can sign a market sharing agreement whereby each firm refrains from entering on the other firm's market. This pairwise relationship is captured by a binary variable, $g_{i j} \in\{0,1\}$. The set of market sharing agreements gives rise to an undirected network $g$ on the set of firms. The total profits of any firm $i$ can be expressed as a function of the network $g$ of market sharing agreements. We denote by $n_{i}(g)$ the number of firms on market $i$, given the network $g$. Total profits are given by the sum of the profits firm $i$ collects on its own market and on all the markets for which it has not signed market sharing agreements:

$$
\Pi_{i}(g)=\pi\left(n_{i}(g)\right)+\sum_{j, g_{i j}=0} \pi\left(n_{j}(g)\right)
$$

\subsection{Efficient and Stable Networks}

Our analysis of the formation of market sharing agreements is based on notions of efficiency and stability. We distinguish between two types of efficiency. A network is efficient if it maximizes total industry profits and socially efficient if it maximizes social welfare. Formally,

Definition 2.1 A network $g$ is efficient if and only if there is no network $g^{\prime}$ such that $\sum_{i} T\left(n_{i}(g)\right)>\sum_{i} T\left(n_{i}\left(g^{\prime}\right)\right)$.

Definition 2.2 A network $g$ is socially efficient if and only if there is no network $g^{\prime}$ such that $\sum_{i} W\left(n_{i}(g)\right)>\sum_{i} W\left(n_{i}\left(g^{\prime}\right)\right)$.

We borrow our concept of stability from Jackson and Wolinsky (1996)'s general study of strategic networks. A network is pairwise stable if no pair of firms wants to establish a new link and no individual firm wants to sever a link. Formally, using the notations $g+g_{i j}$ and $g-g_{i j}$ to denote the network obtained from network $g$ after adding (respectively subtracting) the link $(i, j)$,

Definition 2.3 (Jackson and Wolinsky, 1996) A network $g$ is (pairwise) stable if and only if (i) $\forall i, j \in \mathcal{N}$ s.t. $g_{i j}=1, \Pi_{i}(g) \geq \Pi_{i}\left(g-g_{i j}\right)$ and $\Pi_{j}(g) \geq \Pi_{j}(g-$ $\left.g_{i j}\right)$; and (ii) $\forall i, j \in \mathcal{N}$ s.t. $g_{i j}=0$, if $\Pi_{i}\left(g+g_{i j}\right)>\Pi_{i}(g)$ then $\Pi_{j}\left(g+g_{i j}\right)<$ $\Pi_{j}(g)$. 
The stability notion of Jackson and Wolinsky (1996) is a relatively weak criterion, as firms can only create or sever links one by one. As firms are not allowed to sever more than one link at once, stable networks cannot emerge as the outcome of a noncooperative linking game, where firms choose independently the links they want to form. In order to deal with this problem, we consider an alternative notion of stability, directly related to linking games.

We consider the simultaneous linking game introduced by Myerson (1991). ${ }^{10}$ For each firm $i$, the strategy space $S_{i}$ is the set of all subsets of $N \backslash\{i\}$, i.e., the set of all players with whom $i$ can form links. (We also allow for $s_{i}=\emptyset$, the firm forms no link). A link $g_{i j}$ is formed if and only if $i \in s_{j}$ and $j \in s_{i}$. We let $g\left(s_{1}, \ldots, s_{n}\right)$ denote the graph formed when every firm $i$ chooses $s_{i}$.

Definition 2.4 A strategy profile $\left\{s_{1}^{*}, \ldots, s_{n}^{*}\right\}$ is a (pure strategy) Nash equilibrium of the linking game if and only if for all $i \in \mathcal{N}, \Pi_{i}\left(g\left(s_{i}^{*}, s_{-i}^{*}\right)\right) \geq$ $\Pi_{i}\left(g\left(s_{i}, s_{-i}^{*}\right)\right) \forall s_{i} \in S_{i}$.

The linking game typically admits a large number of Nash equilibria, reflecting coordination failures between two agents who would both benefit from forming a link but do not form it. In order to eliminate this coordination failure, we adopt a refinement which is closely related to Jackson and Wolinsky (1996)'s notion of pairwise stability. We say that an equilibrium is pairwise strong if it is immune to deviations by coalitions of two firms.

Definition 2.5 A strategy profile $\left\{s_{1}^{*}, \ldots, s_{n}^{*}\right\}$ is a pairwise strong Nash equilibrium of the linking game if and only if there does not exist a pair $(i, j)$ of players in $\mathcal{N}$ and strategies $s_{i}$ and $s_{j}$ in $S_{i}$ and $S_{j}$ such that

$$
\begin{aligned}
& \Pi_{i}\left(g\left(s_{i}, s_{j}, s_{-i, j}^{*}\right)\right) \geq \Pi_{i}\left(g\left(s_{i}^{*}, s_{j}^{*}, s_{-i, j}^{*}\right)\right), \\
& \text { and } \begin{cases}\text { either } & \Pi_{i}\left(g\left(s_{i}, s_{j}, s_{-i, j}^{*}\right)\right)>\Pi_{i}\left(g\left(s_{i}^{*}, s_{j}^{*}, s_{-i, j}^{*}\right)\right) \\
\text { or } \quad & \Pi_{j}\left(g\left(s_{i}, s_{j}, s_{-i, j}^{*}\right)\right)>\Pi_{j}\left(g\left(s_{i}^{*}, s_{j}^{*}, s_{-i, j}^{*}\right)\right) .\end{cases}
\end{aligned}
$$

Definition 2.6 A network $g$ is strongly (pairwise) stable if and only if there exists a pairwise strong Nash equilibrium of the linking game, $\left\{s_{1}^{*}, \ldots, s_{n}^{*}\right\}$, such that $g=g\left(s_{1}^{*}, \ldots, s_{n}^{*}\right)$.

\footnotetext{
${ }^{10}$ See Slikker and van den Nouweland (2001) for recent studies of linking games.
} 
Lemma 2.1 Any strongly pairwise stable network is pairwise stable.

Proof. The proof is almost immediate. Suppose that network $g$ is not stable. If $g_{i j}=1$ and $\Pi_{i}(g)<\Pi_{i}\left(g-g_{i j}\right)$ for some $i, j$, firm $i$ would benefit from a unilateral deviation, choosing $s_{i}=s_{i}^{*} \backslash\{j\}$. If $g_{i j}=0, \Pi_{i}\left(g+g_{i j}\right)>\Pi_{i}(g)$ and $\Pi_{j}\left(g+g_{i j}\right) \geq \Pi_{j}(g)$, then $g$ is not immune to a joint deviation by the two firms, $s_{i}=s_{i}^{*} \cup\{j\}, s_{j}=s_{j}^{*} \cup\{i\}$.

\subsubsection{Networks and Graphs}

Before we can characterize efficient and stable collusive networks, we need to introduce some notations and terminology from graph theory. A network is complete if all firms are linked $\left(g_{i j}=1 \forall i, j, i \neq j\right)$ and empty if no firms are linked $\left(g_{i j}=0 \forall i, j\right)$. A firm $i$ is isolated if $g_{i j}=0 \forall j \neq i$. A network $g$ is connected if there exists a path linking any two firms in $g$. A component $g^{\prime}$ of $g$ is a maximally connected subset of $g$. We let $m\left(g^{\prime}\right)$ denote the size of a component $g^{\prime}$, i.e., the number of firms belonging to $g^{\prime}$. A component is complete if all firms inside the component are linked.

We will consider specific networks, called regular networks. A network $g$ is regular of degree $k$, or $k$-regular, if all firms have the same number of links $k$. One of the best known results in graph theory (see, e.g., Lovasz, 1979, p. 249) states:

Lemma 2.2 Consider $k \leq N-1$. If $k N$ is even, there exists a $k$-regular network. Otherwise (i.e., if both $k$ and $N$ are odd), it is possible to form one or two 'almost-regular networks of degree $k$ ', in which all but one firm have degree $k$, and the remaining firm either has degree $(k-1)$ or $(k+1)$.

Figure 1 illustrates these definitions, by presenting some networks for the case $N=6$.

\subsubsection{Efficient Collusive Networks}

The characterization of efficient networks in our model is very simple. As markets are independent, the maximization of total profits or social welfare on all markets amounts to choosing optimal number of firms on each market. Let $n^{P}$ and $n^{O}$ denote the maximizers of $T(n)$ and $W(n)$, respectively. We obtain: 


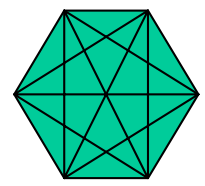

A. Complete network

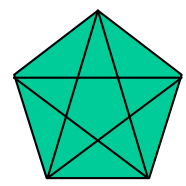

B. Complete component of size 5and an isolated firm

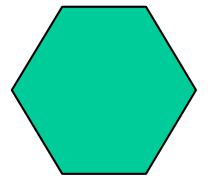

E. 2-regular network (1)

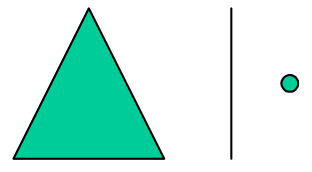

C. Two complete components of sizes 3, 2 and an isolated firm.

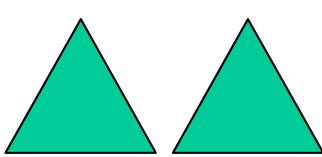

F. 2-regular network (2)

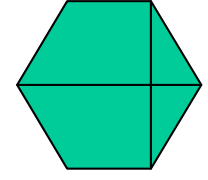

G. Incomplete network 4 firms have 3 links, 2 have 2 .

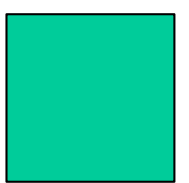

H. Incomplete network. 4 firms have 2 links,

2 have 1 (1)

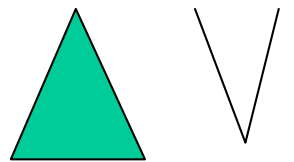

I. Incomplete network. 4 firms have 2 links, 2 have 1. (2)

Figure 1: 
Proposition 2.1 If $N\left(N-n^{P}\right)$ is even, a network is efficient if and only if it is a regular network of degree $N-n^{P}$. If $N\left(N-n^{P}\right)$ is odd and total profits are single-peaked in $n$, a network is efficient if and only if it is an almost regular network of degree $N-n^{P}$. Similarly, if $N\left(N-n^{O}\right)$ is even, a network is socially efficient if and only if it is a regular network of degree $N-n^{O}$. If $N\left(N-n^{O}\right)$ is odd and social welfare is single-peaked in n, a network is efficient if and only if it is an almost regular network of degree $N-n^{0}$

Proof. See Appendix 6.1.

Efficient networks are thus characterized by a strong symmetry property. In efficient or socially efficient networks, all (or almost all) firms have the same number of market sharing agreements, and all (or almost) all markets have the same number of active firms. As Figure 1 shows, there may exist more than one $k$-regular network for fixed values of $N$ and $k .{ }^{11}$ Some $k$-regular networks are connected, others are not ; and the global architecture of $k$-regular networks may vary a lot. When firms and markets are symmetric, in many applications we consider, total profits are decreasing in the number of active firms, and social welfare is increasing. Hence $n^{P}=1$ and $n^{O}=N$, and there is a unique efficient network (the complete network) and a unique socially efficient network (the empty network).

\subsubsection{Stable Collusive Networks}

We now turn to the analysis of stable collusive networks. Applying Jackson and Wolinsky (1996)'s definition to our model, we obtain the following conditions for pairwise stability:

(i) $\forall i, j$ s.t. $g_{i j}=1,\left\{\begin{array}{l}\pi\left(n_{i}(g)\right) \geq \pi\left(n_{i}(g)+1\right)+\pi\left(n_{j}(g)+1\right), \\ \pi\left(n_{j}(g)\right) \geq \pi\left(n_{j}(g)+1\right)+\pi\left(n_{i}(g)+1\right) .\end{array}\right.$

(ii) $\forall i, j$ s.t. $g_{i j}=0, \begin{cases}\text { if } & \pi\left(n_{i}(g)-1\right)>\pi\left(n_{i}(g)\right)+\pi\left(n_{j}(g)\right), \\ \text { then } \quad & \pi\left(n_{j}(g)-1\right)<\pi\left(n_{j}(g)\right)+\pi\left(n_{i}(g)\right) .\end{cases}$

\footnotetext{
${ }^{11}$ In fact, as $N$ becomes large, the number of $k$-regular networks increases dramatically. (See the discussion in Bollobas (1979, p. 158).)
} 
We establish three lemmata that will allow us to characterize the set of stable networks in the benchmark model.

Lemma 2.3 Under Axiom 2.1, if network $g$ is stable, then $\forall i, j \in \mathcal{N}$ s.t. $g_{i j}=$ $1, n_{i}(g)=n_{j}(g)$.

Proof. Since $g$ is stable, Condition (2) is met. Hence, we must simultaneously have $\pi\left(n_{i}(g)\right)>\pi\left(n_{j}(g)+1\right)$ and $\pi\left(n_{j}(g)\right)>\pi\left(n_{i}(g)+1\right)$. By Axiom 2.1, this implies that $n_{j}(g)-1<n_{i}(g)<n_{j}(g)+1 \Leftrightarrow n_{i}(g)=n_{j}(g)$.

Lemma 2.3 shows that when two firms are connected by a market sharing agreement, they must have the same number of active firms on their home market. The intuition underlying this result is easily grasped. By forming a market sharing agreement, a firm benefits from a decrease in the number of competitors on its home market, but loses access to a foreign market. If home markets were asymmetric, the firm with the larger number of competitors on its own market would have no incentive to sign a market sharing agreement, as the profit it makes on the other firm's market is higher than the profit it makes on its home market. While Lemma 2.3 implies that, inside a component of a collusive network, all firms have the same number of links, it does not guarantee that components are complete. Our second lemma establishes this result.

Lemma 2.4 Under Axioms 2.1 and 2.2, if network $g$ is stable, then any component $g^{\prime}$ of $g$ is complete.

Proof. Suppose $g^{\prime}$ is not complete. Then, there exist three firms $i, j, k$ in the component for which $g_{i j}=g_{j k}=1$ and $g_{i k}=0$. Because $g$ is pairwise stable, we know from Lemma 2.3 that $n_{i}(g)=n_{j}(g)=n_{k}(g) \equiv n$. Stability of $g$ also implies that condition (2) holds for $i$ and $j$, while condition (3) holds for $i$ and $k$. That is, $\pi(n) \geq 2 \pi(n+1)$ and $\pi(n-1)<2 \pi(n)$. But this implies $\pi(n) / \pi(n+1)>\pi(n-1) / \pi(n)$, in contradiction to Axiom 2.2 .

Lemma 2.4 shows that whenever two firms are linked to a third by a market sharing agreement, they are also linked among themselves. We interpret this result by stating that firms form complete market sharing alliances, where all members of the alliance agree to stay out of the markets of other alliance members. Notice that the proof of this lemma requires log-convexity of profits. As 
profits are log-convex in the number of active firms, the incentive to enter into a market sharing agreement is higher, the more market sharing agreements the firm has already signed. Hence, in an alliance where, by lemma 2.3, all firms have formed the same number of market sharing agreements, the total number of collusive links must be maximal. The next lemma deals with the existence of distinct components in a stable collusive network.

Lemma 2.5 Under Axioms 2.1 and 2.2, if network $g$ is stable and contains two distinct components $g^{\prime}$ and $g^{\prime \prime}$, then $m\left(g^{\prime}\right) \neq m\left(g^{\prime \prime}\right)$.

Proof. Take two firms $i, j$ in component $g^{\prime}$ and a firm $k$ in $g^{\prime \prime}$. Suppose, by contradiction, that $m\left(g^{\prime}\right)=m\left(g^{\prime \prime}\right)$. Therefore, we have $n_{i}(g)=n_{j}(g)=n_{k}(g) \equiv$ $n$. Stability of $g$ implies that condition (2) holds for $i$ and $j$, while condition (3) holds for $i$ and $k$. That is, $\pi(n) \geq 2 \pi(n+1)$ and $\pi(n-1)<2 \pi(n)$. But this implies $\pi(n) / \pi(n+1)>\pi(n-1) / \pi(n)$, in contradiction to Axiom 2.2.

Lemma 2.5 establishes that, in a stable collusive network, distinct alliances of firms can form, but they must be of different sizes. The asymmetry between alliances is a necessary condition for stability, since firms in two symmetric alliances always have an incentive to form a market sharing agreement by logconvexity of profits. In a stable collusive network with multiple alliances, firms in smaller alliances (with a larger number of competitors on their home market) are reluctant to sign market sharing agreements with firms in larger alliances (with a smaller number of competitors on their home market).

We are now in a position to complete the characterization of pairwise stable collusive networks. Define $m^{*}$ as the minimal integer such that $\pi\left(N-m^{*}+\right.$ 1) $/ \pi\left(N-m^{*}+2\right) \geq 2$. (The existence of a minimal integer $m^{*}$ is guaranteed by log-convexity of profits.) We interpret $m^{*}$ as the minimal size that an alliance must reach so that firms have an incentive to sign market sharing agreements.

Proposition 2.2 Let $m^{*}$ be the minimal integer such that $\pi\left(N-m^{*}+1\right) / \pi(N-$ $\left.m^{*}+2\right) \geq 2$. Under Axioms 2.1 and 2.2, a network $g$ is stable if and only if it can be decomposed into a set of isolated firms and distinct complete components $g_{1}, g_{2}, \ldots, g_{L}$ such that $m\left(g_{l}\right) \neq m\left(g_{l^{\prime}}\right) \forall l \neq l^{\prime}, m\left(g_{l}\right) \geq m^{*} \forall l$. Furthermore, if $m^{*}=2$, there is at most one isolated firm. 
Proof. Lemmata 2.3, 2.4 and 2.5 show that if a network is stable, firms which are not isolated form complete components of different sizes. Furthermore, in a stable network, all firms inside a component must have an incentive to sign a market sharing agreement, and Condition (2) implies that $\pi\left(N-m\left(g_{l}\right)+1\right) \geq 2 \pi\left(N-m\left(g_{l}\right)+2\right) \forall l$. Finally, note that if $m^{*}=2$, there cannot be more than one isolated firm.

Conversely, suppose that the graph $g$ can be decomposed into isolated firms and complete components of different sizes, with $m\left(g_{l}\right) \geq m^{*} \forall l$. We will show that the network is stable. Clearly, as long as $m^{*}>2$, by Condition (3), isolated players have no incentive to create new links. We now consider a link between two players $i$ and $j$ belonging to two components $g_{l}$ and $g_{l^{\prime}}$ with $m\left(g_{l}\right)<m\left(g_{l^{\prime}}\right)$. By Condition (3) again, player $i$, belonging to the smallest component, refuses to form a new link. Finally, as $m\left(g_{l}\right) \geq m^{*} \forall l$, no player inside a component has an incentive to cut a link, and the network is thus stable. Finally, if $m^{*}=2$, any two isolated firms have an incentive to form a link. Hence, there can be at most one isolated firm in a stable network.

Proposition 2.2 provides a full characterization of the pairwise stable networks when firms and markets are symmetric. In a collusive network, all alliances must reach a minimal size (reflecting the fact that the incentives to form market sharing agreements increase with the size of the alliance), alliances must be complete and of different sizes. Typically, stable collusive networks are not unique. There might exist different configurations of alliances which can be sustained in a stable network. In particular, our characterization shows that the number of isolated firms, free-riding on the formation of alliances by other firms, may vary from one configuration to another.

Using Propositions 2.1 and 2.2, we can compare efficient and pairwise stable networks when total profits are single-peaked in the number of active firms. Two cases may arise. If $T(1) \geq T(2)$, then the efficient network is the complete network, and pairwise stable networks necessarily have at least as many links as the efficient network. If, on the other hand, $T(1)<T(2)$, then $\pi(1)<2 \pi(2)$, and the only pairwise stable is the empty network. Again, efficient networks have at least as many links as the pairwise stable network. Hence, we find that pairwise stable networks are always under-connected with respect to efficient 
networks. This result clearly stems from the fact that individual firms have an incentive to free-ride on the formation of market sharing alliances by other firms. ${ }^{12}$ Notice however that we are unable to compare pairwise stable and socially efficient networks, because the social welfare function $W(n)$ typically includes information which is not contained in individual profit functions, $\pi(n)$.

\subsubsection{Strongly Stable Collusive Networks}

Finally, in order to refine the set of pairwise stable collusive networks, we turn to the analysis of strongly pairwise stable networks.

Proposition 2.3 Under Axioms 2.1 and 2.2, a network $g$ is strongly stable if and only if it can be decomposed into a set of isolated firms and distinct complete components $g_{1}, g_{2}, \ldots, g_{L}$ such that (i) $\pi\left(N-m\left(g_{l}\right)+1\right) \geq \pi(N)+$ $\left(m\left(g_{l}\right)-1\right) \pi\left(N-m\left(g_{l}\right)+2\right)$ for all $l$, and (ii) $m\left(g_{l}\right) \neq m\left(g_{l^{\prime}}\right)$ for all $l \neq l^{\prime}$. Furthermore, if $m^{*}=2$, the graph contains at most one isolated firm.

Proof. See Appendix 6.2.

According to Proposition 2.3, strongly stable networks differ from stable networks in the restriction placed on the size of alliances. In a strongly stable network, component sizes must satisfy the very demanding condition: $\pi(N-$ $\left.m\left(g_{l}\right)+1\right) \geq \pi(N)+\left(m\left(g_{l}\right)-1\right) \pi\left(N-m\left(g_{l}\right)+2\right) .{ }^{13}$ To interpret this condition, note that strongly stable collusive networks must be immune to the severance of any number of links by a given firm. If a firm benefits from reneging on a market sharing agreement, it must be willing to renege on all its market sharing agreements, as the profit it makes on a foreign market is always superior to the profit it makes on its home market after severing a link. Hence, the most profitable deviation for a firm is to renege on all its market sharing agreements

\footnotetext{
${ }^{12}$ This result stands in sharp contrast to the two examples discussed in Jackson and Wolinsky (1996). Both in the connections and the co-author models, they show that pairwise stable networks are overconnected with respect to the efficient network. The differences between our results and Jackson and Wolinsky (1996)'s examples are due to differences in the value function of the network in the models.

${ }^{13}$ Because $\pi\left(N-m\left(g_{l}\right)+1\right)-\pi(N)+\left(m\left(g_{l}\right)-1\right) \pi\left(N-m\left(g_{l}\right)+2\right)$ is not monotonic in $m\left(g_{l}\right)$, this condition does not define a lower bound on the sizes of components. In different applications, we will see that this condition often defines an interval of integers.
} 
at once, and in every component, firms must prefer to be linked than to destroy all their links.

Proposition 2.3 also sheds light on the role of bilateralism in the formation of market sharing agreements. If firms were to enter multilateral agreements, by which they agree to share markets with all other members of the alliance, the incentive to defect would be much stronger. In a sense, collusion is easier to sustain with bilateral agreements than with multilateral agreements.

\section{Applications}

\subsection{Cournot Oligopoly with Homogeneous Products}

In our first application, we consider a symmetric Cournot oligopoly with homogeneous products. Letting $q_{i}$ denote the quantity produced by firm $i$ ( $i=$ $1,2, \ldots, n)$ and $Q=\sum q_{i}$ market demand, the Cournot oligopoly is defined by an inverse market demand $P(Q)$ and individual cost functions $c\left(q_{i}\right)$. Each firm's profit on the market is given by

$$
\pi_{i}=q_{i} P(Q)-c\left(q_{i}\right)
$$

We define the elasticity of the slope of the inverse demand function, $E(Q)$ as

$$
E(Q)=\frac{Q P^{\prime \prime}(Q)}{P^{\prime}(Q)}
$$

In an oligopoly model, social welfare is given by total surplus,

$$
W(n)=\int_{0}^{Q^{*}} P(Q) d Q-n c\left(q^{*}\right) .
$$

In the next proposition, we provide sufficient conditions for Axioms 2.1 and 2.2 in the symmetric Cournot model, and derive comparative statics on total industry profits and social welfare.

Proposition 3.1 (i) If costs are increasing and convex and $E(Q)>-1$, individual profits are decreasing in the number of active firms on the market. (ii) If costs are linear, $E(Q)>-1$ and $E^{\prime}(Q) \geq 0$, individual profits are logconvex in the number of active firms on the market. (iii) If costs are linear and $E(Q)>-1$, total profits are decreasing in the number of active firms on the market. (iv) If costs are linear and $E(Q)>-1$, total surplus is increasing in the number of active firms on the market. 
Proof. See Appendix 6.3.

The first statement of the proposition is a classical comparative statics result on Cournot oligopolies (termed "quasi-competitiveness" in Amir and Lambson, 2000). Vives (1999, pp. 105-107) gives early references to this result. Statements (iii) and (iv) are also well-known results, discussed for instance in Vives (1999, pp. 107-109). Statement (ii), providing sufficient conditions for the logconvexity of individual profits, is a new result. While the conditions are clearly very restrictive, we show below that they are satisfied by specific families of inverse demand functions.

\subsubsection{Examples}

Example 3.1 Iso-elastic inverse demand function

Suppose first that demand is given by $P(Q)=1-Q^{\alpha}$ for $\alpha>0$. (If $\alpha=1$, demand is linear; if $0<\alpha<1$, demand is convex, and if $\alpha>1$, demand is concave.) Observe that $E(Q)=\alpha-1$. As $\alpha>0, E(Q)+1>0$ and furthermore, $E^{\prime}(Q) \geq 0$. The sufficient conditions of Proposition 3.1 are thus satisfied. In particular, we know that total profits are decreasing in $n$, so the efficient network is the complete network, and total surplus is increasing in $n$, so the socially efficient network is the empty network. Now, straightforward computations show that

$$
\pi(n)=\alpha n^{\frac{1-\alpha}{\alpha}}(n+\alpha)^{-\frac{1+\alpha}{\alpha}} .
$$

In Appendix 6.4, we show that the only pairwise stable networks are the empty and complete networks for a Cournot oligopoly with isoelastic demand.

Turning now to pairwise strongly stable networks, the complete network is pairwise strongly stable if and only if $\pi(1) \geq \pi(N)+(N-1) \pi(2)$. We show again in Appendix 6.4 that the latter inequality cannot be satisfied for any value of $\alpha$. We conclude that the complete network is never pairwise strongly stable, and hence the only pairwise strongly stable network is the empty network.

Example 3.2 Exponential inverse demand function

Suppose now that the inverse demand is given by $P(Q)=e^{-Q}$. Notice that in that case, $E(Q)=-Q$, and the sufficient conditions of Proposition 3.1 are 
not satisfied. We can still show directly that the equilibrium profit functions are decreasing and log-convex in $n$. Each firm's profit function is given by $\pi(q)=q e^{-Q}$. This profit function is strictly quasi-concave in $q$, and attains a maximum at $q^{*}=1$. We compute the equilibrium profit as $\pi(n)=e^{-n}$. Clearly, $\pi(n)$ is a decreasing function of $n$ and $\log \pi(n)=-n$ is a convex function. Furthermore, $T(n)=n e^{-n}$ is a decreasing function of $n$ (so the efficient network is the complete network) and $W(n)=1-e^{-n}$ is an increasing function of $n$ (so the socially efficient network is the empty network).

Now note that $\pi(n) / \pi(n+1)=e>2, \forall n$. Hence, any two firms have an incentive to form a link, and the set of pairwise stable networks is very large: any network with complete components of different sizes and at most one isolated firm is pairwise stable.

To refine the set of pairwise stable networks, consider now the condition characterizing pairwise strongly stable networks: $\pi(N-m+1)-\pi(N)-(m-$ 1) $\pi(N-m+2) \geq 0$. Define

$$
\begin{aligned}
f(N, m) & =e^{-N+m-1}-e^{-N}-(m-1) e^{-N+m-2} \\
& =e^{-N}\left(e^{m-1}-1-(m-1) e^{m-2}\right) .
\end{aligned}
$$

It is easy to check that $f(N, m) \geq 0$ if and only if $m=2$ or $m=3$. We conclude that in pairwise strongly stable networks, the sizes of components is either equal to 2 or to 3 . The following table characterizes pairwise strongly stable networks for $N=2,3,4,5$ and 6 . For $N \geq 7$; no network is pairwise strongly stable.

\begin{tabular}{|c|c|}
\hline Number of firms & Component sizes \\
\hline 2 & $\{2\}$ \\
3 & $\{3\},\{2,1\}$ \\
4 & $\{3,1\}$ \\
5 & $\{3,2\}$ \\
6 & $\{3,2,1\}$ \\
\hline
\end{tabular}




\subsection{Oligopoly with Heterogeneous Products}

We consider an oligopoly model with differentiated products, where on each market, a representative consumer has a quadratic surplus function given by

$$
U\left(q_{1}, q_{2}, \ldots, q_{n}\right)=\sum_{i=1}^{n} q_{i}-\frac{1}{2}\left(\sum_{i=1}^{n} q_{i}^{2}+d \sum_{j \neq i} q_{i} q_{j}\right)-\sum_{i=1}^{n} p_{i} q_{i},
$$

with $d \in[0,1$. Parameter $d$ is an inverse measure of the degree of differentiation between varieties produced by different firms: they are independent when $d=0$ and perfect substitutes when $d \rightarrow 1$. Maximizing (4) subject to the consumer's budget constraint, yields the linear inverse demand schedule $p_{i}=1-q_{i}-$ $d \sum_{j \neq i} q_{j}$. The demand schedule is then given by $q_{i}=\alpha-\beta p_{i}+\delta \sum_{j \neq i} p_{j}$, where

$$
\alpha=\frac{1}{1+d(n-1)}, \beta=\frac{1+d(n-2)}{(1-d)(1+d(n-1))}, \delta=\frac{d}{(1-d)(1+d(n-1))} .
$$

Assuming that production is costless, Cournot and Bertrand equilibria yield the following results:

$$
\begin{array}{lll}
q_{c}=\frac{1}{2+d(n-1)} & p_{c}=\frac{1}{2+d(n-1)} \quad(\text { Cournot }), \\
q_{b}=\frac{1+d(n-2)}{(1+d(n-1))(2+d(n-3))} & p_{b}=\frac{1-d}{2+d(n-3)} \quad \text { (Bertrand } .
\end{array}
$$

It is readily checked that Axioms 2.1 and 2.2 both hold for $\pi_{c}(n)=p_{c}(n) q_{c}(n)$ and $\pi^{b}(n)=p_{b}(n) q_{b}(n)$. Total surplus is given by

$$
W_{c}(n)=\frac{n(3+d(n-1))}{2(2+d(n-1))^{2}}, W_{b}(n)=\frac{1}{2} \frac{n(3+d(n-4))(1+d(n-2))}{2(2+d(n-3))^{2}(1+d(n-1))} .
$$

Simple computations establish that $W_{c}(n)$ and $W_{b}(n)$ are both increasing in the number of firms, meaning that the socially efficient network is the empty network in both cases.

The following table lists, for $N=6$ and selected values of $d$, the pairwise stable networks and the optimal number of firms under Cournot and Bertrand competition. (The strongly pairwise stable networks are underlined). 


\begin{tabular}{|c|c|c|c|c|}
\cline { 2 - 5 } \multicolumn{1}{c|}{} & \multicolumn{2}{c|}{ Cournot } & \multicolumn{2}{c|}{ Bertrand } \\
\hline$d$ & Pairwise stable networks & $n^{P}$ & Pairwise stable networks & $n^{P}$ \\
\hline 0.9 & $\{6\},\{1,1,1,1,1,1\}$ & 1 & $\{6\},\{1,1,1,1,1,1\},\{5,1\}$ & 1 \\
0.8 & $\{1,1,1,1,1,1\}$ & 2 & $\{6\},\{1,1,1,1,1,1\},\{5,1\}$ & 1 \\
0.7 & $\{1,1,1,1,1,1\}$ & 2 & $\{6\},\{1,1,1,1,1,1\}$ & 2 \\
0.5 & $\{1,1,1,1,1,1\}$ & 3 & $\{1,1,1,1,1,1\}$ & 2 \\
0.1 & $\{1,1,1,1,1,1\}$ & 6 & $\{1,1,1,1,1,1\}$ & 5 \\
\hline
\end{tabular}

As products become more differentiated, collusive networks are harder to sustain. This result is easily interpreted. As products become more differentiated, competition on every market becomes less fierce. Hence, the benefit of a market sharing agreement, resulting in a reduction in the number of competitors on the home market, is reduced, and the cost, measured by the profit forlorn on foreign markets is increased. Furthermore, as products become more differentiated, the efficient number of firms on each market, $n^{P}$ increases, so that the efficient networks (the $N-n^{P}$ regular networks) become more sparse. This result is also very intuitive. In a model with differentiated products, an increase in the number of firms leads to an expansion of demand. When products become more differentiated, this expansion of demand is more pronounced and overcomes the effect of a reduction in competition on total industry profits. Finally, not surprisingly, for any fixed value of product differentiation $d$, collusion is easier to sustain under price competition than under quantity competition. This result is reminiscent of the literature on cartels where Deneckere and Davidson (1985) show that full collusion is a stable outcome under price competition, while it cannot be sustained under quantity competition.

\subsection{Auctions}

In this application, we consider a set of firms, $i=1,2, \ldots, N$, participating in procurement auctions. For each auction, firm $i$ draws a cost parameter $c_{i}$ distributed according to the common distribution function $F\left(c_{i}\right)$ with continuous density $f\left(c_{i}\right)$ over the support $[0, C]$. Furthermore, suppose that the function $J(c)=c+\frac{F(c)}{f(c)}$ is increasing in $c$ for any $c \in[0, C]$. For the sake of simplicity, we assume that the buyer sets a reservation price at $C$, and we consider any auction setting which allocates the contract to the lowest bidder. By the 
revenue-equivalence theorem (see, e.g. Riley and Samuelson, 1981, Proposition 1, p. 383), the ex ante expected payoff of every firm is independent of the auction rule, and is equal to

$$
\pi(n)=\frac{1}{n}\left(E\left(c_{n}^{2}\right)-E\left(c_{n}^{1}\right)\right),
$$

where $c_{n}^{i}$ denotes the $i$-th order statistic among $n$ draws from the common distribution $F$. By a simple application of the theory of order statistics (see Mac Afee and Mac Millan, 1988, Lemma 1, p.103), $E\left(c_{n}^{2}\right)=E\left(J\left(c_{n}^{1}\right)\right)$. Hence,

$$
\begin{aligned}
\pi(n) & =\frac{1}{n} E\left(\frac{F\left(c_{n}^{1}\right)}{f\left(c_{n}^{1}\right)}\right) \\
& =\int_{0}^{C}(1-F(c))^{n-1} F(c) d c .
\end{aligned}
$$

Concerning social welfare, we distinguish between two measures of welfare: the expected gain of the buyer and the total surplus generated in the auction. The following proposition shows that Axioms 2.1 and 2.2 are always satisfied in private value auctions, and provides comparative statics on total profits and social welfare.

Proposition 3.2 In a private value procurement auction,ex ante individual profits are strictly decreasing and strictly log-convex in the number of active firms on the market. Furthermore, total profits are strictly decreasing in the number of active firms on the market. The expected gain of the buyer and the expected total surplus are increasing in the number of active firms on the market.

Proof. See Appendix 6.5.

The comparative statics effects of an increase in the number of bidders on individual profits, total profits and social surplus are well-known in auction theory (see Mac Afee and Mac Millan (1987, p. 711) and the references therein). The log-convexity of individual profits in the number of bidders is an original result, providing a strong structural condition on the effect of an increase in the number of bidders on individual profits. Proposition 3.2 shows that, in a procurement auction, the efficient network is the complete network, and the socially efficient network is empty. We now illustrate our results with two examples. 


\subsection{Examples}

\section{Example 3.3 Uniform distribution}

In this case, $F(c)=c$ for all $c \in[0,1]$. We obtain:

$$
\pi(n)=\frac{1}{n(n+1)}
$$

It is easy to see that $\pi(2) / \pi(3)=2$. Hence, there are three pairwise stable network architectures: the complete network, the empty network and a network with one component of size $N-1$ and an isolated bidder. Straightforward computations show that the complete network is pairwise strongly stable if and only if $N \leq 3$ and that the network with one component of size $N-1$ is never pairwise strongly stable.

\section{Example 3.4 Exponential distribution}

Now, $F(c)=1-e^{-c}$ for $c \in[0,+\infty)$.We obtain

$$
\pi(n)=\frac{1}{n(n-1)} \text { for } n>1 \text { and } \pi(1)=+\infty .
$$

By analogy with the previous example, we see that $\pi(3) / \pi(4)=2$. Hence, there are four pairwise stable network architectures: the complete network, the empty network and networks with components of sizes $N-1$ or $N-2$. Notice that the complete network is strongly pairwise stable, the network with a component of size $N-1$ is pairwise strongly stable if and only if $N \leq 4$ and the network with a component of size $N-2$ is never pairwise strongly stable.

\section{Extensions}

In this section, we extend our baseline model by allowing for asymmetries between firms and markets. We first consider the case where markets are symmetric, but each firm benefits from an incumbency advantage on its own market. We then study a situation where all firms are symmetric, but markets are different. 


\subsection{Incumbency Advantage}

Firms involved in market sharing agreements generally justify market sharing by the presence of large entry costs into foreign markets. In order to analyze the validity of this argument, we consider two models where incumbents benefit from an advantage in their home market. In the first model, firms face a fixed entry cost to enter foreign markets. In the second model, firms incur a unit transportation cost when selling in a market different from their home market.

\subsubsection{Fixed Entry Costs}

We denote by $K$ the fixed entry cost into foreign markets. As we want to abstract from situations where firms face exogenous barriers to entry, we suppose that the fixed cost is lower than the lowest possible profit on each market, i.e., $K<\pi(N)$. Under this condition, we can easily generalize Lemma 2.3 to show that any two firms linked by a market sharing agreement have the same number of active firms on their home markets.

Lemma 4.1 Suppose that $K<\pi(N)$. Under Axiom 2.1, if network $g$ is stable, then $\forall i, j \in \mathcal{N}$ s.t. $g_{i j}=1, n_{i}(g)=n_{j}(g)$.

Proof. With fixed costs, a network is pairwise stable if and only if the following conditions hold:

(i) $\forall i, j \in \mathcal{N}$ s.t. $g_{i j}=1$,

$$
\left\{\begin{array}{l}
\pi\left(n_{i}(g)\right) \geq \pi\left(n_{i}(g)+1\right)+\pi\left(n_{j}(g)+1\right)-K \\
\pi\left(n_{j}(g)\right) \geq \pi\left(n_{j}(g)+1\right)+\pi\left(n_{i}(g)+1\right)-K
\end{array}\right.
$$

(ii) $\forall i, j \in \mathcal{N}$ s.t. $g_{i j}=0$,

$$
\begin{cases}\text { if } & \pi\left(n_{i}(g)-1\right)>\pi\left(n_{i}(g)\right)+\pi\left(n_{j}(g)\right)-K, \\ \text { then } & \pi\left(n_{j}(g)-1\right)<\pi\left(n_{j}(g)\right)+\pi\left(n_{i}(g)\right)-K .\end{cases}
$$

Suppose by contradiction that $g_{i j}=1$, and $n_{i}(g)+1 \leq n_{j}(g)$. Then by Axiom $2.1, \pi\left(n_{j}(g)\right) \leq \pi\left(n_{i}(g)+1\right)$. Furthermore, as $K<\pi(N), \pi\left(n_{j}(g)+1\right)-K>0$ and the second inequality of Condition (6) is violated.

However, the characterization result of Proposition 2.2 cannot be generalized to the case of fixed entry costs. Formally, a characterization of stable networks 
under entry costs requires a condition on individual profits which is stronger than log-convexity, namely $2 \pi(n+1)-\pi(n)>2 \pi(n)-\pi(n-1) \forall n .{ }^{14}$ This condition is violated in most applications we have considered.

While we are unable to obtain a full characterization of stable collusive networks, we remark that the presence of fixed costs makes market sharing agreements more attractive to firms, as the benefit of the agreement on the home market remains the same, but the loss on foreign markets is reduced. Hence, we expect that market sharing agreements are easier to sustain when firms benefit from an incumbency advantage on their home market. In particular, whenever the complete network is stable without entry costs, it is also stable once entry costs are introduced. ${ }^{15}$ In general, as the following example illustrates, the presence of fixed entry costs generates pairwise stable and strongly stable networks with a denser set of market sharing agreements.

Example 4.1 Linear Cournot model with fixed entry costs

Consider a Cournot oligopoly with $N=6$, zero marginal cost and a linear inverse demand $P=10-Q$. We compute

$$
\begin{aligned}
\pi^{i}\left(n_{i}\right) & =\frac{100}{\left(n_{i}+1\right)^{2}}, \pi^{j}\left(n_{i}\right)=\frac{100}{\left(n_{i}+1\right)^{2}}-K, \\
T\left(n_{i}\right) & =n_{i} \frac{100}{\left(n_{i}+1\right)^{2}}-\left(n_{i}-1\right) K, W\left(n_{i}\right)=\frac{50 n_{i}\left(n_{i}+2\right)}{\left(n_{i}+1\right)^{2}}-\left(n_{i}-1\right) K .
\end{aligned}
$$

It is easily seen, in this example, that $2 \pi(n)-\pi(n-1)$ is not monotonic in $n$, so we cannot apply a general method to characterize pairwise stable networks. Instead, we compute directly the set of stable networks by following two steps. We first characterize the set $\mathcal{I}$ of integers for which $\pi(n)-2 \pi(n+1) \geq K$. In any stable collusive network, the sizes of home markets must belong to that set, so we can, in this first step, eliminate a number of possible networks. In the second step, we continue to eliminate candidate stable networks by checking

\footnotetext{
${ }^{14}$ To see that this condition is stronger than log-convexity, note that if $2 \pi(n+1)-\pi(n)>$ $2 \pi(n)-\pi(n-1)$, then$$
\pi(n)\left(2 \frac{\pi(n+1)}{\pi(n)}-1\right)>\pi(n-1)\left(2 \frac{\pi(n)}{\pi(n-1)}-1\right) .
$$

Assuming that the profit function is decreasing in $n$, this implies that it is log-convex in $n$.

${ }^{15}$ The complete network is stable if and only if $\pi(1) \geq 2 \pi(2)$. But then, $\pi(1) \geq 2 \pi(2)-K$ for any $K$, and the complete network is also stable with entry costs.
} 
the conditions for stability (Conditions (5) and (6)). It turns out that all stable networks are formed of complete components, so we can characterize a stable network by component sizes.

It is easily checked that $T(n)$ is a decreasing function, so the efficient network is the complete network. Total surplus $W(n)$ is a concave function, attaining its maximum at $n^{O}=\sqrt[3]{100 / K}-1$. The following table lists, for selected values of $K$, the set of integers $\mathcal{I}$,the pairwise stable and strongly stable networks (pairwise strongly stable networks are underlined), and the optimal number of firms on each market.

\begin{tabular}{|l|l|l|l|}
\hline Fixed cost & $\mathcal{I}$ & Pairwise stable networks & $n^{O}$ \\
\hline$K=0$ & 1 & $\{6\}, \underline{, 1,1,1,1,1,1\}}$ & 6 \\
$K=0.5$ & 1 & $\{6\}, \underline{\{1,1,1,1,1,1\}}$ & 5 \\
$K=1$ & 1 & $\{6\}, \underline{\{1,1,1,1,1,1\}}$ & 5 \\
$K=1.5$ & $1,2,5$ & $\{6\},\{5,1\}, \underline{\{2,2,2\}}$ & 4 \\
$K=2$ & $1,2,3,4,5$ & $\{6\},\{5,1\},\{4,2\}, \underline{,\{, 2,1\}}$ & 4 \\
\hline
\end{tabular}

For small values of the fixed cost $(K=0.5$ and 1$)$, the situation is similar to the baseline model with $K=0$. Stable networks are either complete or empty, and the only strongly stable network is empty. By contrast, when $K=2$, any market sharing agreement is profitable, and stable networks can be formed with any combination of components of different sizes. In that case, the strong stability criterion imposes an upper bound on the sizes of components, and only one network survives this criterion. Interestingly, there exists an intermediate case, $K=1.5$, where, in a stable collusive network, firms either form large or small components. The strongly stable network is then obtained with firms entering exactly one market sharing agreement.

Socially efficient networks are 1-regular networks for $K=0.5,1$ and 2regular networks for $K=1.5,2$. Hence, in the presence of fixed costs, pairwise stable networks are not necessarily more connected than socially efficient networks. In fact, all pairwise strongly stable networks are under-connected with respect to the socially efficient network. Our example thus suggests that the line of defense adopted by firms involved in market sharing agreements may rest on solid ground. 


\subsubsection{Transportation costs}

We assume now that firms incur a unit transportation cost, denoted $t>0$, when selling on a foreign market. Consider a homogeneous Cournot market with inverse demand given by $P(Q)=1-Q$. Again, to abstract from situations where firms face exogenous barriers to entry, we assume that $t<1 / N$. The profit levels for domestic and foreign firms are respectively

$$
\pi_{d}(n)=\left(\frac{1+(n-1) t}{n+1}\right)^{2} \quad \text { and } \quad \pi_{f}(n)=\left(\frac{1-n t}{n+1}\right)^{2} .
$$

There exists no general method to compute pairwise stable collusive networks in this example. (In particular, two firms may be linked but have different numbers of competitors on their home markets.) We note that, as in the case of fixed entry costs, collusion is easier to sustain when firms face transportation costs in foreign markets. In our example, this is reflected by the following two facts.

- The complete network is always pairwise stable. Stability of the complete network requires $\pi_{d}(1) \geq \pi_{d}(2)+\pi_{f}(2) \Longleftrightarrow(1 / 36)(10 t+1)(1-2 t) \geq$ 0 , which is satisfied since, by assumption, $t<1 / N<1 / 2$.

- The empty network is pairwise stable if and only if $t$ is low enough. Stability of the empty network requires $\pi_{d}(N-1)<\pi_{d}(N)+\pi_{f}(N) \Longleftrightarrow$ $t<\bar{t}(N)$, where $\bar{t}(N)$ reaches a maximum for $N=5(\bar{t}(5)=0.063)$ and then decreases with $N$.

Other stable networks may emerge for different values of $t$. Suppose that $N=6$. It is easily checked that the $1-$ regular network is stable for $0.0608 \leq$ $t<0.0631$. Incomplete networks may also be pairwise stable. For $0.0631 \leq t<$ 0.107, incomplete networks with 4 firms having 2 links and 2 firms 1 (networks $\mathrm{H}$ and $\mathrm{I}$ in Figure 1) are pairwise stable. For $0.107 \leq t<1 / 6$, the incomplete network with 4 firms having 3 links and 2 firms 2 (network G in Figure 1) is pairwise stable.

\subsection{Asymmetric markets}

We now consider a model where firms are symmetric, but markets are different. Furthermore, we suppose that markets can be ranked according to profitability. 
Either $\pi_{i}(n) \leq \pi_{j}(n)$ for all $n$ or $\pi_{i}(n) \geq \pi_{j}(n)$ for all $n$. We show that, in a pairwise stable network, firms with less profitable home markets always sign more market sharing agreements.

Lemma 4.2 Suppose that $\pi_{i}(n) \geq \pi_{j}(n)$ for all $n$ and that $g_{i j}=1$. Then, under Axiom 2.1, if network $g$ is pairwise stable, then $n_{i}(g) \geq n_{j}(g)$.

Proof. The pairwise stability conditions are given by

(i) $\forall i, j \in \mathcal{N}$ s.t. $g_{i j}=1$,

$$
\left\{\begin{array}{l}
\pi_{i}\left(n_{i}(g)\right) \geq \pi_{i}\left(n_{i}(g)+1\right)+\pi_{j}\left(n_{j}(g)+1\right), \\
\pi_{j}\left(n_{j}(g)\right) \geq \pi_{j}\left(n_{j}(g)+1\right)+\pi_{i}\left(n_{i}(g)+1\right) .
\end{array}\right.
$$

(ii) $\forall i, j \in \mathcal{N}$ s.t. $g_{i j}=0$,

$$
\begin{cases}\text { if } & \pi_{i}\left(n_{i}(g)-1\right)>\pi_{i}\left(n_{i}(g)\right)+\pi_{j}\left(n_{j}(g)\right), \\ \text { then } & \pi_{j}\left(n_{j}(g)-1\right)<\pi_{j}\left(n_{j}(g)\right)+\pi_{i}\left(n_{i}(g)\right) .\end{cases}
$$

Since $\pi_{i}(n) \geq \pi_{j}(n) \forall 1 \leq n \leq N$, the most stringent of the two conditions (7) is $\pi_{j}\left(n_{j}(g)\right) \geq \pi_{j}\left(n_{j}(g)+1\right)+\pi_{i}\left(n_{i}(g)+1\right)$. For this condition to hold, we must have $\pi_{j}\left(n_{j}(g)\right)>\pi_{i}\left(n_{i}(g)+1\right)$ which, from Axiom 2.1, is equivalent to $n_{j}(g)<n_{i}(g)+1$.

Lemma 4.2 is easily interpreted. A firm with a less profitable market only has an incentive to sign a market sharing agreement with a firm on a more profitable market if the profits it makes on the foreign market is smaller than the profit it makes on the home market. Hence, for a link to be stable, it must be that the number of competitors is larger on the more profitable market. Notice in particular that Lemma 4.2 allows for the formation of incomplete collusive networks, where different firms form different numbers of agreements. This is illustrated in Example 4.2, where an incomplete alliance is formed in a pairwise stable collusive network.

Example 4.2 Asymmetric markets and Bertrand competition.

Suppose that there are three markets: two identical "large" markets and one "small" market. Bertrand competition with differentiated products takes place on each market. Demand on the large markets is given by $p_{i}=20-q_{i}-$ 
$0.5 \sum_{j \neq i} q_{j}$. Demand on the small market is given by $p_{i}=15-q_{i}-0.8 \sum_{j \neq i} q_{j}$. Profits on the two types of markets are given in the following table.

\begin{tabular}{c|cc}
$n$ & $\pi_{L}(n)$ & $\pi_{S}(n)$ \\
\hline 1 & 100 & 56.25 \\
2 & 59.30 & 17.36 \\
3 & 37.5 & 7.79
\end{tabular}

It is easy to see that large markets are more profitable than the small market. Furthermore, we claim that a network where the firm on the small market is linked to both firms on large markets, but firms on large markets are not linked to another, is stable. To check this claim, notice that (i) the small firm does not wish to sever its market sharing agreements with the large firms: $\pi_{S}(1) \geq \pi_{S}(2)+\pi_{L}(3)$; (ii) the large firms do not wish to severe their market sharing agreement with the small firm: $\pi_{L}(2) \geq \pi_{S}(2)+\pi_{L}(3)$; and (iii) the large firms do not wish to sign a market sharing agreement with each other: $\pi_{L}(1)<2 \pi_{L}(2)$.

\section{Conclusion}

This paper analyzes the formation of market sharing agreements among firms in oligopolistic markets and procurement auctions. The set of market sharing agreements defines a collusive network, and the paper provides a complete characterization of stable and efficient collusive networks when firms and markets are symmetric. Efficient networks are regular networks, where firms have the same number of market sharing agreements. Stable networks are formed of complete alliances, of different sizes, larger than a minimal threshold. Typically, stable networks display fewer market sharing agreements than the optimal network for the industry and more market sharing agreements than the socially optimal network. When firms or markets are asymmetric, incomplete alliances can form in stable networks, and stable networks may be under-connected with respect to the social optimum.

Our analysis sheds light on the recent wave of market sharing agreements in the chemical and airline industries. We find that, in order to be stable, alliances must reach a minimum size, and that an alliance grouping all firms in the 
industry (as in the chemical industry) is more likely to be stable. When different alliances form (as in the airline industry), the market sharing agreements must be complete - all firms in the alliance are linked by market sharing agreements - and different alliances must have different sizes, with firms in smaller alliances free-riding on the formation of market sharing agreements by other firms. Our study also shows unambiguously that, in a symmetric setting, the formation of market sharing alliances is harmful and should be corrected by an adequate antitrust policy. On the other hand, when firms face entry costs in foreign markets, the formation of market sharing agreements may be beneficial, as it helps to correct excessive entry of firms into foreign markets.

While we believe that our analysis provides a useful application of recent developments in the theory of economic networks to a concrete problem in industrial organization, we are aware of two important shortcomings of our study. First, in order to keep the problem tractable and concentrate on the formation of collusive networks, we assume that each firm is originally associated to one market. This assumption is reasonable in an international oligopoly setting, where firms have a clearly specified home market, but is more difficult to justify in procurement auctions, where firms are rarely specialized on one particular auction. We believe that the thrust of our analysis remains unchanged if we assume that there are more firms than markets or more markets than firms. However, the exact characterization of pairwise stable collusive networks in these situations poses new challenges and requires further study. Second, and most importantly, we suppose that market sharing agreements are enforceable, without explicitly modelling a dynamic framework of interaction. The analysis of the enforceability of market sharing agreements seems to us to be a particularly promising area of research. By forming market sharing agreements, firms can choose the number of markets on which they will compete, and hence endogenously determine the level of multimarket contact. We plan to tackle this issue by studying the formation and enforceability of market sharing agreements in a repeated interaction setting in future research. 


\section{Appendix}

\subsection{Proof of Proposition 2.1}

We only consider the case of total profits. (A similar argument applies for social welfare.) Let $k^{P}=N-n^{P}$. We distinguish between two cases.

(1) If $N k^{P}$ is even, by Lemma 2.2, there exists a regular network $g$ of degree $k^{P}$. For this network, $\sum_{i} T\left(n_{i}(g)\right)=N T\left(N-k^{P}\right)=N T\left(n^{P}\right)$. For any other network $g^{\prime}, \sum_{i} T\left(n_{i}\left(g^{\prime}\right)\right)-\sum_{i} T\left(n_{i}(g)\right)=\sum_{i}\left(T\left(n_{i}\left(g^{\prime}\right)\right)-T\left(n^{P}\right) \leq 0\right.$, as $n^{P}$ is a maximizer of $T(n)$.

(2) If now $N$ and $k^{P}$ are odd, there is no regular network of degree $k^{P}$. Furthermore, as $N$ and $k^{P}$ are both odd, $k^{P} \neq N-1$ and $k^{P} \neq 0$, so the function $T(n)$ is neither monotonically decreasing nor increasing. As $T(n)$ is single-peaked, it reaches a maximum at $n^{P}$ and the second highest value is reached at either $\left(n^{P}-1\right)$ or $\left(n^{P}+1\right)$. In order to maximize $T(n)$ on all markets, we need to assign $n^{P}$ firms to $(N-1)$ markets and either $\left(n^{P}-1\right)$ or $\left(n^{P}+1\right)$ to one market. Hence, the efficient network is an almost regular network of degree $\left(N-n^{P}\right)$.

\subsection{Proof of Proposition 2.3}

Consider a pairwise strong Nash equilibrium $s^{*}$. By Lemma 2.1, $g\left(s^{*}\right)$ is a pairwise stable network, and can be decomposed into complete components of sizes greater than $m^{*}$. Suppose, by contradiction, that some component $g_{l}$ does not satisfy the condition: $\pi\left(N-m\left(g_{l}\right)+1\right) \geq \pi(N)+\left(m\left(g_{l}\right)-1\right) \pi\left(N-m\left(g_{l}\right)+2\right)$. Then we claim that $s^{*}$ cannot be a Nash equilibrium, as any firm $i$ in $g_{l}$ has a profitable deviation by choosing $s_{i}^{\prime}=\emptyset$.

Conversely, suppose that the graph $g$ can be decomposed into a set $I$ of isolated firms and disjoint complete components $g_{1}, g_{2}, \ldots, g_{L}$ such that $m\left(g_{l}\right) \neq$ $m\left(g_{l^{\prime}}\right) \forall l \neq l^{\prime}$, and $\pi\left(N-m\left(g_{l}\right)+1\right) \geq \pi(N)+\left(m\left(g_{l}\right)-1\right) \pi\left(N-m\left(g_{l}\right)+2\right) \forall l$. Consider the following strategies for the firms: If firm $i$ belongs to a component $g_{l}$, it announces $s_{i}^{*}=\left\{j \mid j \in g_{l}, j \neq i\right\}$. If $i$ is isolated, it announces $s_{i}^{*}=\emptyset$. We show that these strategies form a pairwise strong Nash equilibrium. Clearly, no firm $i$ has an incentive to create a link to a firm $j$ in another component, as $i \notin s_{j}^{*}$. Furthermore, as $m\left(g_{l}\right) \neq m\left(g_{l^{\prime}}\right) \forall l \neq l^{\prime}$, no pair of firms has an incentive 
to create an additional link. Now consider a firm's incentive to destroy some links. As $\pi\left(N-m\left(g_{l}\right)+1\right) \geq \pi(N)+\left(m\left(g_{l}\right)-1\right) \pi\left(N-m\left(g_{l}\right)+2\right)$, the firm cannot benefit from destroying all its links. So suppose that it chooses to destroy links to a strict subset $J$ of firms in $g_{l}$. This deviation would be profitable if and only if

$$
\pi\left(N-m\left(g_{l}\right)+1\right)<\pi\left(N-m\left(g_{l}\right)+1+|J|\right)+|J| \pi\left(N-m\left(g_{l}\right)+2\right) .
$$

Since $|J| \geq 1$, we have that

$$
\pi\left(N-m\left(g_{l}\right)+|J|+1\right)+|J| \pi\left(N-m\left(g_{l}\right)+2\right) \leq(|J|+1) \pi\left(N-m\left(g_{l}\right)+2\right) .
$$

Furthermore, as $J$ belong is a strict subset of firms in $g_{l},|J|<m\left(g_{l}\right)-1$, and $|J|+1 \leq m\left(g_{l}\right)-1$. So,

$$
(|J|+1) \pi\left(N-m\left(g_{l}\right)+2\right) \leq\left(m\left(g_{l}\right)-1\right) \pi\left(N-m\left(g_{l}\right)+2\right) .
$$

But then, combining (9), (10), and (11), we obtain $\pi\left(N-m\left(g_{l}\right)+1\right)<\left(m\left(g_{l}\right)-\right.$ 1) $\pi\left(N-m\left(g_{l}\right)+2\right)$, contradicting our original condition.

\subsection{Proof of Proposition 3.1}

As the other results are well-known, we concentrate on the proof of statement

(ii). Differentiating individual profits with respect to $q_{i}$, we obtain the firstorder condition:

$$
P^{\prime}(Q) q_{i}+P(Q)-c^{\prime}\left(q_{i}\right)=0
$$

As all firms are identical, we write $q_{i}=q_{j}=q \forall i, j$, so that

$$
P^{\prime}(Q) q+P(Q)-c^{\prime}(q)=0 .
$$

Treating $n$ as a continuous variable and assuming linear costs, we obtain, by an implicit differentiation of Equation (12):

$$
\frac{\partial q}{\partial n}=-\frac{q}{n} \frac{Q P^{\prime \prime}(Q)+n P^{\prime}(Q)}{Q P^{\prime \prime}(Q)+(n+1) P^{\prime}(Q)},
$$

yielding

$$
(n-1) \frac{\partial q}{\partial n}+q=\frac{q}{n} \frac{Q P^{\prime \prime}(Q)+2 n P^{\prime}(Q)}{Q P^{\prime \prime}(Q)+(n+1) P^{\prime}(Q)} .
$$


Rearranging,

$$
(n-1) \frac{\partial q}{\partial n}+q=\frac{Q}{n^{2}} \frac{(2 n+E(Q)}{(1+E(Q)+n)}
$$

Hence,

$$
\frac{d \pi(n)}{d n}=\frac{Q^{2} P^{\prime}(Q)(2 n+E(Q))}{n^{3}(1+E(Q)+n)} .
$$

Differentiating this expression again with respect to $n$, we get:

$$
\frac{d^{2} \pi(n)}{d n^{2}}=\frac{A(n)}{n^{6}(1+E(Q)+n)^{2}},
$$

where

$$
\begin{aligned}
A(n)= & {\left[n^{3}(1+E(Q)+n)\right]\left[Q^{2} P^{\prime}(Q)\left(2+E^{\prime}(Q) \frac{d Q}{d n}\right)+(2 n+E(Q)) \frac{d Q}{d n} \frac{d Q^{2} P^{\prime}(Q)}{d Q}\right] } \\
& -\left[(2 n+E(Q)) Q^{2} P^{\prime}(Q)\right]\left[3 n^{2}(1+E(Q)+n)+n^{3}\left(1+E^{\prime}(Q) \frac{d Q}{d n}\right)\right] .
\end{aligned}
$$

As costs are linear, $c(q)=c^{\prime}(q) q$. Hence $\pi(n)=q\left(P(Q)-c^{\prime}(q)\right)=-\frac{Q^{2}}{n^{2}} P^{\prime}(Q)$.

We thus have:

$$
\pi(n) \frac{d^{2} \pi(n)}{d n^{2}}-\left(\frac{d \pi(n)}{d n}\right)^{2}=\frac{-Q^{2} P^{\prime}(Q)\left[A(n)+n^{2}(2 n+E(Q))^{2} Q^{2} P^{\prime}(Q)\right]}{n^{8}(1+E(Q)+n)^{2}} .
$$

Using Equation (15), in order to show that $\pi(n)$ is log-convex, it suffices to establish

$$
A(n)+n^{2}(2 n+E(Q))^{2} Q^{2} P^{\prime}(Q) \geq 0 .
$$

Now,

$$
\frac{d Q}{d n} \frac{d Q^{2} P^{\prime}(Q)}{d Q}=\frac{Q^{2} P^{\prime}(Q)(2+E(Q))}{n(1+E(Q)+n)} .
$$

Hence,

$$
\begin{aligned}
A(n)= & Q^{2} P^{\prime}(Q)\left[2 n^{3}(1+E(Q)+n)+n^{2}(2 n+E(Q))(2+E(Q))\right. \\
& \left.-3 n^{2}(1+E(Q)+n)(2 n+E(Q))-n^{3}(2 n+E(Q))\right] \\
& +Q^{2} P^{\prime}(Q) E^{\prime}(Q) \frac{d Q}{d n}\left[n^{3}(1+E(Q)+n)-n^{3}(2 n+E(Q))\right] \\
= & Q^{2} P^{\prime}(Q)\left[-n^{2}\left(6 n^{2}+6 n E(Q)+2 E(Q)^{2}+E(Q)\right]\right. \\
& -Q^{2} P^{\prime}(Q) E^{\prime}(Q) \frac{d Q}{d n} n^{3}(n-1) .
\end{aligned}
$$


Rearranging,

$$
\begin{aligned}
A(n)+n^{2}(2 n+E(Q))^{2} Q^{2} P^{\prime}(Q)= & -Q^{2} P^{\prime}(Q) n^{2}\left[E^{\prime}(Q) \frac{d Q}{d n} n(n-1)\right. \\
& \left.+\left(E(Q)^{2}+(2 n+1) E(Q)+2 n^{2}\right)\right]
\end{aligned}
$$

By assumption, $E^{\prime}(Q) \geq 0$. Furthermore, $E(Q)^{2}+(2 n+1) E(Q)+2 n^{2}>0$ $\forall n \geq 2$ and $\forall E(Q)$. Hence, as $P^{\prime}(Q)<0$ we obtain

$$
A(n)+n^{2}(2 n+E(Q))^{2} Q^{2} P^{\prime}(Q)>0,
$$

showing that the profit function $\pi(n)$ is log-convex.

\subsection{Iso-elastic Inverse Demand Function}

We claim that in a Cournot model with iso-elastic demand:

$$
\frac{\pi(1)}{\pi(2)}>2>\frac{\pi(2)}{\pi(3)} \text {. }
$$

The left inequality is immediately obtained: as $T(1)>T(2)$. The right inequality is equivalent to $\log 2+\log \pi(3)-\log \pi(2)>0$, which can be rewritten as

$$
f(\alpha) \equiv(2 \alpha-1) \log 2+(1-\alpha) \log 3-(1+\alpha) \log \left(\frac{3+\alpha}{2+\alpha}\right)>0 .
$$

Immediate computations show that $f^{\prime \prime}(\alpha)>0$ and $f^{\prime}(0)=3 \log 2-2 \log 3+$ $1 / 6>0$. Hence $f(\alpha)$ is a strictly increasing function and, as $f(0)=0$, we conclude that $f(\alpha)>0$ for all $\alpha \in(0,+\infty)$. Hence, the only pairwise stable networks are the empty and complete networks for a Cournot oligopoly with isoelastic demand.

Turning now to pairwise strongly stable networks, define $g(N)=\pi(N)+$ $(N-1) \pi(2)$. The second derivative is given by $g^{\prime \prime}(N)=\pi^{\prime \prime}(N)$. As $\pi$ is logconvex, it is necessarily convex, so $g^{\prime \prime}(N)>0$. Furthermore, evaluating $g^{\prime}(N)$ at the lower bound $N=2$, we obtain

$$
g^{\prime}(2)=\pi^{\prime}(2)+\pi(2)=\alpha(1+\alpha) 2^{\frac{1-2 \alpha}{\alpha}}(2+\alpha)^{-\frac{1+2 \alpha}{\alpha}}>0 .
$$

Hence $g(N)$ is a strictly increasing function, and, if the complete network is pairwise strongly stable for some $N \geq 3, \pi(1) \geq \pi(3)+2 \pi(2)$. Furthermore, as $\pi(3)>\pi(2) / 2$, we obtain:

$$
\pi(1)>\frac{5}{2} \pi(2)
$$


We finally show that inequality (16) is never satisfied. Rewriting it, we obtain:

$$
h(\alpha)=\alpha \log 5+(1-2 \alpha) \log 2-(1+\alpha) \log \left(\frac{2+\alpha}{1+\alpha}\right)<0 .
$$

It is easy to see that $h^{\prime \prime}(\alpha)>0$ and $h^{\prime}(0)=\log 5-3 \log 2+0.5>0$. Hence, $h(\alpha)$ is an increasing function and, as $h(0)=0$, inequality (16) can not be satisfied for any value of $\alpha$. We conclude that the complete network is never pairwise strongly stable, and hence the only pairwise strongly stable network is the empty network.

\subsection{Proof of Proposition 3.2}

We concentrate again on the log-convexity of profits, as the other statements of the proposition can be obtained using well-known arguments. A direct computation shows that

$$
\pi^{\prime}(n)=\int_{0}^{C} \log (1-F(c))(1-F(c))^{n-1} F(c) d c<0 .
$$

To show that profits are log-convex, compute

$$
\pi^{\prime \prime}(n)=\int_{0}^{C}\left(\log (1-F(c))^{2}(1-F(c))^{n-1} F(c) d c .\right.
$$

Define $p(c)=(1-F(c))^{n-1} F(c)$ and $g(c)=-\log (1-F(c))$. The function $p$ is finite and strictly positive over $(0, C)$ and the function $g$ is finite and nonnegative over the same set. Hence, we may define, as in Hardy, Littlewood and Polya (1952, p.134), the weighted integral mean of the function $g$ as

$$
\mathcal{M}_{r}(g, p)=\left(\frac{\int p(c) g^{r}(c) d c}{\int p(c) d c}\right)^{\frac{1}{r}}
$$

By a generalization of Schwartz's inequality (Theorem 192, p. 143 in Hardy, Littlewood and Polya, 1952), if $r<s$,

$$
\mathcal{M}_{r}(g, p)<\mathcal{M}_{s}(g, p)
$$

Applying this result to the special case $r=1, s=2$, we obtain:

$$
\left(\int p(c) g(c)\right)^{2} d c<\int p(c) d c \int p(c) g(c)^{2} d c .
$$


Replacing $p$ and $g$ with their expressions:

$$
\begin{aligned}
& \left(\int_{0}^{C} \log (1-F(c))(1-F(c))^{n-1} F(c) d c\right)^{2} \\
< & \int_{0}^{C}(1-F(c))^{n-1} F(c) d c \int_{0}^{C}\left(\log (1-F(c))^{2}(1-F(c))^{n-1} F(c) d c .\right.
\end{aligned}
$$

Hence

$$
\pi^{\prime}(n)^{2}<\pi(n) \pi^{\prime \prime}(n)
$$

showing that individual profits are strictly log-convex in $n$. 


\section{References}

[1] Amir, R., Lambson, V.E. (2000). On the effects of entry in Cournot markets. Review of Economic Studies 67, 235-254.

[2] d'Aspremont C., Jacquemin, A., Gabszewicz, J.J., Weymark, J. (1983). On the Stability of Collusive Price Leadership. Canadian Journal of Economics $16,17-25$.

[3] Australian Broadcasting Corporation (2000). Simsmetal fined $\$ 2$ million for market sharing attempt. Available at www.abc.net.au/pm/s142195.htm.

[4] Australian Competition and Consumer Commission (1998). ACCC institutes on collusion allegations. Available at www.accc.gov.au/media/mr1998/ mr220-98.html.

[5] Australian Competition and Consumer Commission (1999). ACCC alleges market sharing agreement between regional newspapers result of misuse of market power. Available at www.accc.gov.au/media/mr-127-99.htm.

[6] Bala, V., Goyal, S. (2000).A Noncooperative Model of Network Formation, Econometrica 68, 1181-1231.

[7] Bloch, F. (1997). Noncooperative models of coalition formation in games with spillovers. In C. Carraro and D. Siniscalco, eds,. New Directions in the Economic Theory of the Environment. Cambridge University Press.

[8] Bollobas, B. (1979). Graph Theory: An Introductory Course, New York: Springer Verlag.

[9] Deneckere, R., Davidson, R. (1985). Incentives to form Coalitions with Bertrand Competition. Rand Journal of Economics 16, 473-486.

[10] Goyal, S. (1993) Sustainable Communications Networks. Tinbergen Institute Discussion Paper TI 93-250.

[11] Goyal, S., Moraga, J. L. (2000). R\&D Networks. Working paper. Erasmus University. 
[12] Goyal, S., Joshi, S. (2000a) Networks of Collaboration in Oligopoly. Working Paper. Erasmus University Rotterdam.

[13] Goyal, S., Joshi, S. (2000b). Bilateralism and Free trade. Working paper. Erasmus University Rotterdam.

[14] Hardy, G.H., Littlewood, J.E., Pólya, G. (1952). Inequalities. Cambridge: Cambridge University Press.

[15] Irish Competition Authority (1999). Cartel Watch. Competition Authority Guidelines on Cartels: Detection and Remedies. Available at www.irlgov.ie/compauth/CARTEL.htm

[16] Jackson, M.O., Wolinsky, A. (1996). A strategic model of social and economic networks. Journal of Economic Theory 71, 44-74.

[17] Lovasz, L. (1979). Combinatorial problems and exercises. Amsterdam: North-Holland.

[18] Mailath, G., Zemsky, P. (1991). Collusion in Second Price Auctions with Heterogeneous Bidders. Games and Economic Behavior 3, 467-486.

[19] Maxwell, W., Reznick, R. (2000). Competition law: Guardian of the digital marketplace. Available at www.hugheshubbard.com/data/whatnew/ Publications\%20(New)/hotdata/ebus.htm.

[20] McAfee, P.R., McMillan, J. (1987). Auctions and Bidding. Journal of Economic Literature 25, 699-738.

[21] McAfee, P.R., McMillan, J. (1988). Search mechanisms. Journal of Economic Theory 44, 99-123.

[22] McAfee, P.R., McMillan, J. (1992). Bidding rings. American Economic Review 82, 579-599.

[23] Myerson, R.B. (1991). Game theory: Analysis of conflict. Cambride, MA: Harvard University Press.

[24] Nocke, V. (1999).Cartel Stability under Capacity Constraints: The Traditional View Restored 
STICERD Discussion Paper EI/23, London School of Economics.

[25] Pesendorfer, M. (2000). A study of collusion in first-price auctions. Review of Economic Studies 67, 381-411.

[26] Riley, J., Samuelson, W. (1981). Optimal Auctions. American Economic Review. 71, 381-392.

[27] Scherer, F.M., Ross, D. (1990). Industrial market structure and economic performance. Boston: Houghton Mifflin.

[28] Selten, R. (1973). A Simple Model of Imperfect Competition when 4 are Few and 6 are many. International Journal of Industrial Organization 2, 141-201.

[29] Slikker, M., van den Nouweland, A. (2001).Social and Economic Networks in Cooperative Game Theory. Boston: Kluwer Academic Publishers.

[30] Stigler, G. (1950). Monopoly and Oligopoly by Merger. American Economic Review 40, 23-34.

[31] Vives, X. (1999). Oligopoly pricing. Cambridge, MA: MIT Press.

[32] Yi, S. S. (1997). Stable Coalition Structures with Externalities. Games and Economic Behavior 20, 201-237. 


\section{Q Queen Mary \\ University of London}

This working paper has been produced by the Department of Economics at Queen Mary, University of London

Copyright @ 2001 Paul Belleflamme and Francis Bloch All rights reserved.

\section{Department of Economics}

Queen Mary, University of London

Mile End Road

London E1 4NS

Tel: +44 (0)20 78825096 or Fax: +44 (0)20 89833580

Email: j.conner@qmw.ac.uk

Website: www.econ.qmw.ac.uk/papers/wp.htm 